Dept. of Anatomy and Histology

Fac. Vet. Med., Assiut University

\title{
MORPHOLOGICAL AND MORPHOMETRICAL STUDIES ON THE NON-AMPULLATED PART OF THE DUCTUS DEFERENS OF THE DONKEY \\ (EQUUS ASINUS)
}

(With I Table, 2 Histograms and 21 Figures)

$$
\text { By }
$$

A.O. SALEM

(Received at 31/3/2003)

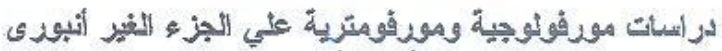

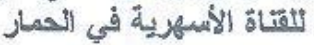

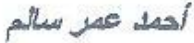

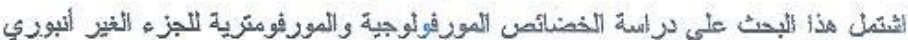

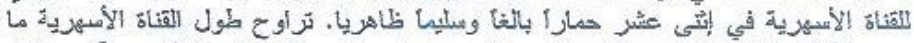

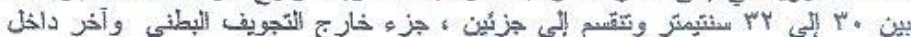

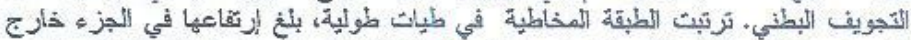

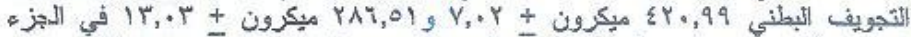

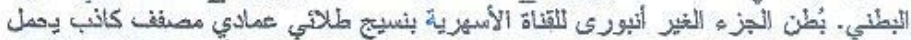

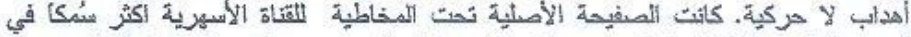

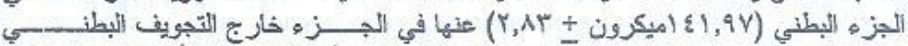

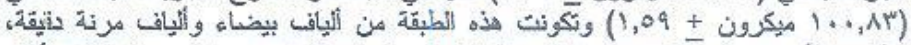

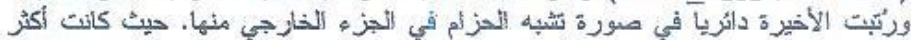

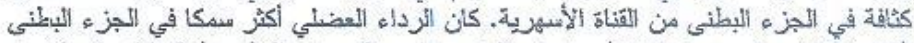

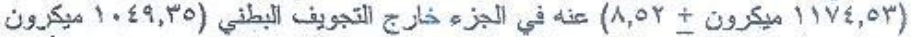

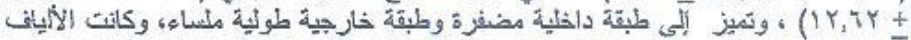

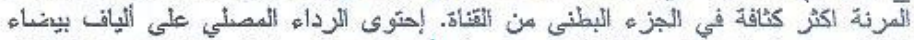

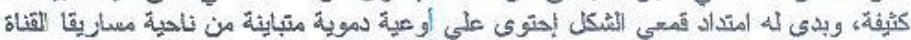

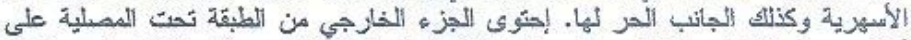

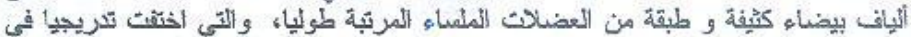

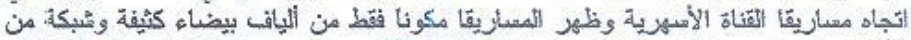

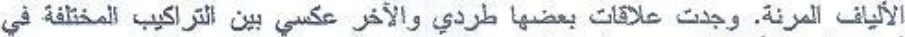

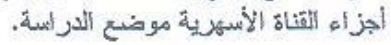




\section{SUMMARY}

This investigation included the study of the morphological and morphometrical characteristics of the non-ampullated part of the ductus deferens of twelve adult apparently healthy donkeys. The ductus deferens measured about $30-32 \mathrm{~cm}$. in length. It was divided into an extra-abdominal and an abdominal part. The ductus deferens was characterized by folded mucosa. The mucosal folds were higher in the extra-abdominal ( $420.99 \mu \mathrm{m} \pm 7.03)$ than in the abdominal part $(286.51$ um \pm 13.03$)$ of the duct. The ductus deferens was lined with pseudostratified columnar epithelium carrying stereocilia. The lamina propria-submucosa was thicker in the abdominal $(141.97 \mu \mathrm{m} \pm 2.83)$ than in the extra-abdominal part $(100.83 \mu \mathrm{m} \pm 1.59)$. It was consisted of dense collagenous and fine elastic fibers. The latter were arranged in a girdle-like manner in the outermost part of this layer and appeared more numerous in the abdominal part of the vas deferens. The tunica muscularis was thicker in the abdominal $(1174.53 \mu \mathrm{m} \pm 8.52)$ than in the extra-abdominal part of the duct (1049.35 $\mu \mathrm{m} \pm 12.62)$. It was characteristically arranged into an inner interwoven and an outer longitudinal layer of smooth muscle fibers, containing more elastic fibers in the abdominal part. The tunica serosa was consisted mainly of dense collagenous with few elastic fibers. It was expanded at the mesoductus and its opposite side, containing various supplying vessels. The outer part of the subserosal layer appeared denser and contained a continuous, layer of longitudinally oriented smooth muscle fibers. The latter disappeared gradually towards the mesoductus, where it appeared consisting mainly of dense collagenous and network of elastic fibers. Some direct and inversed correlations were found between the structures of the studied parts of the non-ampullated part of the ductus deferens.

Key words: Morphology, morphometry, ductus deferens, donkey.

\section{INTRODUCTION}

The ductus deferens is a muco-muscular tube, which at the time of ejaculation propels the epididymal content into the ejaculatory duct. There were only few reports concerning the histomorophology of the ductus deferens (Trotter, 1959; Hamilton and Cooper, 1978; AbdelRaouf and Hassan, 1981; Pal and Bharadwaj, 1985; Goswami, Yashwant Singh and Nagpal, 1994). With regard to equines, Ellery (1971) gave little information on the ductus deferens of stallions. Therefore, this study was undertaken to give some information on the variations in the 
histomorphological and morphometrical features of the non-ampullated part of the ductus deferens in the donkey.

\section{MATERIAL and METHODS}

The present study was carried out on the non-ampullated part of the ductus deferens of 12 apparently healthy donkeys (Equus asinus). Four donkeys were used for studying anatomical features of the ductus deferens. The animals were anaesthetized, thoroughly bled to death from the common carotid artery, perfused with $10 \%$ formalin and then dissected. Small pieces were collected from the extra-abdominal and abdominal parts of the ductus deferens from the other 8 donkeys, fixed in Bouin's fixatives, and processed for paraplast embedding. 5-7 um thick sections were cut and stained.

For general histomorphology, haematoxylin and eosin, (Harris, 1900), Verhoeff's haematoxylin (Verhoeff, 1908), Crossmon's trichrome (Crossmon's, 1937) and Gomori's reticulin (Gomori, 1937) were used.

For transmission electron microscopy of the lining epithelium, especially the principal cells and their cilia, small pieces of the mucosa of ductus deferens were fixed in half-strength karnovsky fixative for 4 hours at $4^{\circ} \mathrm{C}$ (karnovsky, 1965). Thenafter they were post-fixed in $1 \%$ Osmic tetroxide in $0.1 \mathrm{M}$ Na-cacodylate buffer for further 2 hours at $4^{\circ} \mathrm{C}$ and processed for Epon-Araldite embedding. Ultrathin sections were stained with uranyl acetate and lead nitrate and examined under JEOL $100 \mathrm{CX}$ II transmission electron microscope.

For morphometrical studies, the duct luminal diameter, height of the mucosal folds, epithelium and stereocilia, the thickness of the lamina propria-submucosa, tunica muscularis and the tunica serosa were measured. These measurements were carried out on fifteen fields along the stained histological sections of the studied parts of each animal, using Leica Q $500 \mathrm{MC}$ Image analyser. These measurements were statistically analysed.

\section{RESULTS}

Grossly, the non-ampullated part of the Ductus deferens of the adult donkey was the longest part of the duct, where it measured about 30 to $32 \mathrm{~cm}$. in length. It was suspended within a serosal fold for its own, the mesoductus. The ductus deferens was consisted of abdominal and extra-abdominal parts. The extra-abdominal part extended from the tail of the epididymis, as a tortuous tube then became straighter in its 
course till the vaginal ring as the non-vascular part of the spermatic cord. The abdominal part was shorter, where it measured about 10 to $11.5 \mathrm{~cm}$. in length. It extended from the vaginal ring and reached the dorsal surface of the urinary bladder, where it formed the Ampulla ductus deferentis (Fig. 1).

Microscopically, the non-ampullated part of the vas deferens of the donkey consisted of three circumferentially arranged layers around a central circular lumen: Tunica mucosa, Tunica muscularis and Tunica serosa. The latter formed cone-shaped expansions at the mesoductus and also at its opposite side harbouring the supplying vessels (Fig. 2). The lumen of the ductus deferens appeared wider at the extra-abdominal (Fig. 3) than at the abdominal one (Fig. 4), where it measured 1031.79 $\mu \mathrm{m} \pm 16.95$ and $649.06 \mu \mathrm{m} \pm 5.09$, respectively (Table 1 \& Histogram 1).

\section{I- Tunica mucosa:}

The mucosal tunic of the vas deferens was thrown into welldeveloped irregular longitudinal folds, which sometimes branch and anastomose with each other. They were of variable height, where they reached their maximum height $(420.99 \mu \mathrm{m} \pm 7.03)$ at the extraabdominal part, while at the abdominal part, they measured $286.51 \mu \mathrm{m}$ \pm 13.03 in height (Table 1, Histogram 1 \& Figs. 3-7).

\section{a) Epithelium mucosae:}

The non-ampullated part of the vas deferens of the donkey was lined with pseudostratified columnar variety studded with stereocilia. The epithelium appeared higher in the extra-abdominal $(22.97 \mu \mathrm{m} \pm$ 0.59) than in the abdominal part, where it measured $17.51 \mu \mathrm{m} \pm 0.19$ in height (Table 1 \& Histogram 1). The epithelium consisted of tall columnar principal cells and short basal ones. The former cells contained slightly basophilic cytoplasm and basally located somewhat oval nucleus with distinct nucleolus and densely-stained coarse chromatin (Fig. 4 Inset). In both parts of the vas deferens the epithelium decreased gradually in height towards the tip of the mucosal folds. At the ultrastructural level, the principal cells were provided with stereocilia and contained pinocytotic vesicles in their apical regions, that confirmed the light microscopical results (Fig. 5). The stereocilia of the principal cells were long $(9.75 \mu \mathrm{m} \pm 0.23)$ in the extra-abdominal part of the ductus deferens. They became fewer and shorter $(5.88 \mu \mathrm{m} \pm 1.57)$ at the abdominal part. Generally, these stereocilia became also shorter and fewer towards the tip of the folds or disappeared from some areas in both parts of the ductus. The basal cells were generally oval or spherical 
with slightly basophilic cytoplasm and contained ovoid or spherical nucleus with prominent nucleolus (Fig. 4 Inset).

b) Lamina propria-submucosae:

The lamina propria-submucosa increased in thickness at the abdominal part of the ductus deferens, where it reached $141.97 \mu \mathrm{m}$ 2.83 in thickness, while at the extra-abdominal part, it was $100.83 \mu \mathrm{m} \pm$ 1.59 in thickness (Table 1 , Histogram 1 \& Figs. $2-4,6 \& 7$ ). This layer was consisted of dense connective tissue containing coarse collagenous and fine elastic fibers. The latter did not extend into the core of the mucosal fold but they formed a network circumferentially arranged around the lumen, in a girdle-like manner in the outermost part of the lamina propria (Figs. 8 \& 9). Few fine elastic fibers were observed also extending into the muscular layer. These elastic fibers appeared denser within the lamina propria-submucosa of the extra-abdominal part of the ductus deferens (Fig. 9).

Reticular fibers were demonstrated in the vicinity of the epithelial lining (Fig. 10). Smooth muscle fibers were singly scattered in the outermost part of the lamina propria-submucosa but did not extend into the core of the mucosal folds (Figs. $6 \& 7$ ). In addition to the fibroblasts and lymphocytes, numerous venules and arterioles as well as blood capillaries were observed within this layer.

II- Tunica muscularis:

The tunica muscularis was the thickest layer of the nonampullated part of the ductus deferens of the donkey. At the abdominal, it was thicker $(1174.53 \mu \mathrm{m} \pm 8.52)$ than at the extra-abdominal part, where it reached $1049.35 \mu \mathrm{m} \pm 12.62$ in thickness (Table 1 \& Histogram 1). It was consisted of two layers of smooth muscle fibers. The inner muscular layer was arranged in an interwoven manner, so that, their bundles appeared in various sectioning planes, while the outer layer was consisted of longitudinally arranged muscle bundles (Figs. 2 \& 11-13). Some individual oblique or circularly arranged bundles of the inner extended into the outer layer (Fig. 12). The muscle bundles of both layers were surrounded by coarse collagenous (Figs. 2- 4, $12 \& 13$ ) and few, fine elastic fibers (Fig. 9). The proportion of the latter fibers was higher within the muscular layer of the abdominal part of the vas deferens (Fig. 9). Reticular fibers, however, arranged in a delicate network, were demonstrated surrounding individual muscle fibers (Fig. 13). Branches of nerve fibers as well as arterioles, venules and capillaries were observed in the tunica muscularis. Some bundles of the outer longitudinal muscular layer were demonstrated extending into the 
subserosa towards the cone-shaped expansion of the mesoductus (Figs. 2 $\& 15)$.

\section{III- Tunica serosa:}

The non-ampullated part of the ductus deferens of the donkey was enclosed entirely within a serosal fold (Fig. 2). The tunica serosa was greatly variable in thickness, where it measured $200.50 \mu \mathrm{m}$ 20.30 and $243.95 \mu \mathrm{m} \pm 9.66$ in thickness at the medio-lateral axis of the extra-abdominal and abdominal part of the ductus deferens, respectively (Table $1 \&$ Histogram 1 ). The tunica serosa was consisted of an outer mesothelial covering and a dense submesothelial connective tissue layer. This subserosal layer expanded at both the mesoductus as well as the opposite side (free border), where it reached $1350.40 \mu \mathrm{m} \pm$ 3.93 in thickness, containing numerous small-sized arteries and veins as well as venules, arterioles, capillaries, lymph vessels and nerve fibers (Figs. 2, 14 \& 15). Branches from these vessels were observed surrounding the muscular coat (Fig. 2).

The subserosal layer was consisted of dense connective tissue formed mainly of coarse collagenous fibers. At its outer part, the collagenous fibers appeared denser forming band-like structure containing a thick continuous layer of longitudinally oriented smooth muscle fibers (Figs. 2, 11 \& $14-17$ ). The latter were characteristically smaller in size than those of the muscular coat (Figs. 14-17) and formed a thick muscular bundle at the opposite side (frec border) of the mesoductus (Figs. 2 \& 14). The amount of these muscles decreased gradually in the direction of the mesoductus, and totally disappeared within it (Figs. 2, $14 \& 15$ ). On the other hand, few fine elastic fibers began to appear at the opposite side of the mesoductus (Fig. 18) which increased gradually (Fig.19) in amount towards the mesoductus (Fig. 20 ), replacing the muscle fibers within the subserosa. Consequently, the mesoductus appeared consisting mainly of dense band-like collagenous with a network of elastic fibers, covered on both surfaces with mesothelium (Figs. 2, 15, $20 \& 21$ ).

\section{DISCUSSION}

The present study revealed that, the mucosa of the nonampullated part of the ductus deferens of the aduit donkey was longitudinally folded. Similar results were reported by Niemi (1965) and Kennedy (1978) in rats, Ellery (1971) in stallions, Osman and Fahmy (1970) and Pal and Bharadwaj (1985) in buffaloes, Ham and Cormack (1979), Weiss (1983) and Fawcett (1994) in man, Smolich 
and Michel (1985), Liebich (1990) as well as Wrobel and Dellmant (1993) in domestic animals and Goswami et al. (1994) in camels.

In agreement with Goswami et al. (1994) in camels, there was a regional variation in the height of the mucosal folds of the ductus deferens, where they: were higher in the extra-abdominal (420.99 $\mu \mathrm{m} \pm$ 7.03) than in abdominal part of the vas deferens of the donkey (286.51 $\mu \mathrm{m} \pm 13.03$ ).

The obtained results revealed, that the luminal diameter of the extra-abdominal part of the vas deferens of the donkey was wider (1031.79 $\mu \mathrm{m} \pm 16.95)$ in comparison with the abdominal one (649.06 $\mu \mathrm{m} \pm 5.09)$. Similar regional variations were recorded also by Kennedy (1978), Pal and Bharadwaj (1985) and Goswami et al. (1994) in rats, buffaloes and camels, respectively.

There was a direct correlation between the width of luminal diameter and the height of the mucosal folds. It could be suggested that, the heigher mucosal folds need more space and consequently wider lumen, otherwise these folds may lead to more narrowing the lumen and impairing its function.

It may be suggested also that, the wider lumen of the extraabdominal part of the ductus deferens is important in receiving more rapidly, the massive epididymal content at the onset of ejaculation with a minimal tensile strength.

On the other hand, the narrower lumen of the abdominal part may probably help in keeping the forcing power of the ejaculated sperms during their passage within this terminal part as equal as that of the extra-abdominal part, with the aid of the somewhat thick muscular coat in the abdominal part of the ductus deferens.

The non-ampullated part of the donkey ductus deferens was lined with pseudostratified columnar epithelium studded with stereocilia as confirmed by the transmission electron microscopy. These results simulated, that mentioned by Osman and Fahmy (1970) in buffaloes; Ali, Tingari and Moniem (1978) and Goswami et al. (1994) in camels, Murakami, Sugita and Hamasaki (1982) in man and monkeys as well as Smollich and Michel (1985); Liebich (1990); Banks (1993) and Wrobel and Dellmann (1993) in domestic animals.

In agreement with $\mathrm{Pal}$ and Bharadwaj (1985) in buffaloes, the epithelial lining of the extra-abdominal part of the vas deferens was higher than that of the abdominal one. These results disagree with that observed by Hoffer and Greenberg (1978) in guinea pigs, Kennedy and Heidger (1979) in rats and Goswami et al. (1994) in camels. 
In accordance with Ramos (1979) in monkeys and Goswami et al. (1994) in camels, the stereocilia of the prinicpal cells were long in the extra-abdominal part of the vas deferens of the donkey. This disagrees with that observed by Kennedy and Heidger (1979) in rats.

In agreement with Hermo and de Melo (1987) and Andonian and Hermo (1999a), the principal cells of the donkey vas deferens have an absorptive function as supported by the presence of numerous pinocytotic vesicles in the cell apical region. They suggested that, these cells eliminate water from the lumen of the duct during and after ejaculation into the underlying vascular channel in the lamina propriasubmucosa in order to concentrate the sperms. This was supported by Krstic (1984), Liebich (1990), Hess and Sinowatz (1992), Hess (1996), Lohiya, Srivastava, Ansari and Manivannan (1999) and Srivastava, Ansari and Lohiya (2000) that, the stereocilia participate in the secretory and absorptive functions.

The present results revealed that, there is a direct correlation between the height of the epithelial cells and the length of the stereocilia (indicating cellular activity) from one side, as well as the height of the mucosal folds and the width of the luminal diameter from the other side (increased surface area). These parameters were higher in the extraabdorninal than in the abdominal part, which may reflect a high absorotive capacity within the extra-abdominal than in the abdominal part of the ductus deferens.

In agreement with Pal \& Bharadwaj (1985) in buffaloes, the lamina propria-submucosa was thicker in the abdominal part of the ductus deferens of the donkey. There was an inversed correlation between the thickness of the lamina propria-submucosa and the height of the mucosal folds. This may be attributed to, a certain amount of the connective tissue is needed to fill the core of the large mucosal folds, leading subsequently to decrease the thickness of the lamina propriasubmucosa in that part of the vas deferens.

The lamina propria-submuosa of the ductus deferens of the donkey was composed of dense connective tissue layer containing mainly coarse collagenous and dense-network of elastic fibers. This agree with that mentioned by Trautman and Fiebiger (1957), Smollich and Michel (1985), and Wrobel and Dellmann (1993) in domestic animals, Ham and Cormack (1979), Schiebler and Peiper (1984) and Fawcett (1994) in man, as well as Pal and Bharadwaj (1985) in buffaloes. However, Banks (1993) in domestic animals and Goswami et 
al. (1994) in camels mentioned that, the elastic fibers were absent within this layer.

On the basis of the great elasticity of the elastic fibers and their capability for expansion about 150 times its original length, to which they return when released (Liebich, 1990), it could be speculated that, the specific girdle-like arrangement of these fibers gives the vas deferens great elasticity to counteract the mechanical stress exerted by the luminal content from one side and the powerful muscular contraction from the opposite side. Consequently, this arrangement probably acts as absorbing shock for stretch and compression.

Reticular fibers were demonstrated within the lamina propriasubmucosa of the ductus deferens of buffaloes (Pal and Bharadwaj, 1985) and camels (Goswami et al., 1994). In the vas deferens of the donkey, they were localized only in the vicinity of the epithelium lining as revealed by positive reactivity for silver staining, and were considered as integrated part of the basement membrane (Fawcett, 1994).

The tunica muscularis of the vas deferens of the donkey was oriented into a characteristic inner interwoven and an outer longitudinal layer of smooth fibers. Trautman and Fiebiger (1957) as well as Wrobel and Dellmann (1993) in stallions, bulls, boars and carnivores mentioned that, the muscular coat consists of intermingled circular, longitudinal and oblique layers. In camels, the muscular coat was arranged in an inner circular and an outer longitudinal layer (Ali et al., 1978; Goswami et al., 1994). While, Hoffer and Greenberg (1978) in guinea pigs, Osman and Fahmy (1970) and Pal and Bharadwaj (1985) in Buffaloes, Fawcett (1994) in man and Lohiya et al. (1999) in monkeys observed that, the muscular coat of the ductus deferens was consisted of inner and outer longitudinal and middle circular layers of smooth muscle fibers.

The muscular coat of the vas deferens of the donkey contained elastic fibers, which increased in amount in the abdominal part. These fibers give this terminal part more elasticity, which may facilitate the passage of the ejaculated sperms.

Contrary to that observed by Goswami el al. (1994) in camels, the tunica muscularis of the ductus deferens of the donkey was thicker in the abdominal than in the extra-abdominal part. It could be suggested that, the increased thickness of the muscular coat in the abdominal part of the vas deferens, may assist in maintaining the speed of ejaculated sperms within this part as nearly as that of the initial part.

The present study revealed that, the outer part of the subserosal layer was composed of coarse collagenous fibers, forming band-like 
structures, containing longitudinally oriented bundles of smooth muscle fibers. Trautman and Fiebiger (1957) in domestic animals and Pal and Bharadwaj (1985) in buffaloes mentioned that, the tunica serosa contains bundles of smooth muscle fibers. Wrobel and Dellmann (1993) stated that the perimetrium contains similarly smooth muscle fibers, which continue with that of the broad ligament of the uterus. Schummer, Nickel and Sack (1979) added that, these muscles are continuous with the outer longitudinal layer of the uterus. This disagrees partially with the obtained results, where these fibers were small in size and showed no continuation to the outer longitudinal layer of the vas deferens, moreover they were not observed within the mesoductus.

The presence of longitudinally oriented muscle bundles within the serosa of the ductus deferens of the donkey, probably enable it to accommodate itself with the shortening and lengthening action, exerted by contraction of the muscular coat during ejaculation.

The unique (band-like) arrangement of dense collagenous fibers in the outer layer of the subserosa may indicate that, this layer lay under tension and consequently need more support and great resistance to the pulling force.

Within the mesoductus, the longitudinally arranged muscular bundles were disappeared and replaced with numerous elastic fibers. So the mesoductus became consisting entirely of dense collagenous fibers and network of elastic ones. From this structural characteristic and on the basis of the great elasticity of the elastic fibers and the great tensile strength of the collagenous ones, which reach $6 \mathrm{gk} / \mathrm{mm}^{2}$ (Hess, 1996), it could be speculated, that these features make the mesoductus stronger enough and somewhat elastic to counteract the shortening and lengthening of the long vas deferens, caused by the powerful muscular contraction during ejaculation.

\section{ACKNOWLEDGEMENT}

I would like to thank Prof. Dr. Y.A. Abdel-Rahman, Department of Anatomy and Histology, Facuity of Veterinary Medicine, Assiut University, for valuable comment.

\section{REFERENCES}

Abdel-Raouf, M. and Hassan, A.H.S. (1981): The postnatal development of the ductus deferens and ampulla in bulls. Z. Mikrosk. Anat. Forsch. Leipzig., 95: 785-796. 
Ali, H.A.; Tingori, M.D. and Moniem, K.A. (1978): On the morphology of the accessory male glands and histochemistry of the ampulla ductus deferentis of the camel (Camelus dromedarius) J. Anat., 12: $277-290$.

Andonian, S. and Hermo, L. (1999a): Principal cells of the vas deferens are involved in water transport and steroid synthesis in the adult rat. J. Androl., 20: $158-176$.

Banks, W.J. (1993): Applied veterinary histology. $3^{\text {Tc }}$ Ed. Mosby Year Book. St. Louis. Baltimore Boston. Chicago. London Philadelphia. Sydney. Toronto.

Crossmon, $G$. (1937): A modification of Mallory's connective tissue stain with a discussion of the principles involved. Anat. Rec., 69: $33-38$.

Ellery, J.C. (1971): Spermatogenesis, accessory sex gland histology and the effects of seasonal change in the stallion. Ph D. Thesis. Fac, Graduate School Univ. Minnesota.

Fawcett, D.W. (1994): A textbook of histology. In Bloom, W. and Fawcett, D.W. $12^{\text {th }}$ Ed. W.B. Saunders Co. Philadelphia.

Gomori, G. (1937): Silver impregnation of reticulum in paraffin sections, Am. J. Pathol.,13: 993-1002. Cited by Bancroft, J.D.; Stevens, A. and Turner, D.R. (1996): In theory and practice of histological techniques. $4^{\text {th }}$ Ed. Churchill. Livingstone. New York. Edinburgh. London. Madrid. Melbourne Sanfrancisco. Tokyo.

Goswami, S.K.; Yashwant Singh and Nagpal, S.K. (I994): Histological and histochemical studies in ductus deferens of camel: Nonglandular part. Indian J. Animal Sci., 64: 1328 - 1331.

Ham, A.W. and Cormack, D.H. (1979): Histology, $8^{\text {th }}$ Ed. J.B. Lippincott Co. Philadelphia. Toronto.

Hamillon, D.W. and Cooper, T.G. (1978): Gross and histological variations along the length of the rat vas deferens. Anat. Rec., 190: $795-810$.

Harris, H.F. (1900): On the rapid conversion of haematoxylin into haematein in staining reactions. J. Appl. Microsc. Lab. Methods, 3: 777-780. Cited by Bancroft, et al. (1996).

Hees, H. (1996): Grundriss und Atlas der Mikroskopischen Anatomie des Menschen. Band 1: Zytologie und Allgemeine Histologie. 12 Aufl. Gustav Fischer Verlag. Stuttgart. Jena. New York. 
Hees, H. and Sinowatz, F. (1992): Histologie, kurzlehrbuch der Zytologie und mikroskopischen Anatomie. 2 Aufl. Deutscher Ärzte-Verlag.

Hermo, L. and de Melo, V. (1987): Endocytic apparatus and transcytosis in epithelial cells of the vas deferens in the rat. Anat. Rec., 217: $153-163$.

Karnovsky, M.J. (1965): A formaldehyde-glutaraldehyde fixative of high osmolarity for use in electron microscopy. J.Cell Biol., 27: 137A$138 \mathrm{~A}$.

Hoffer, A.P. and Greenberg. J. (1978): The structure of the epididymis, efferent ductules and ductus deferens of the guinea pig: A light microscope study. Anat. Rec., 190: 659-678.

Kennedy, S.W. (1978): Regional variations in the rat vas deferens. Anat. Rec, 190: 442 .

Kennedy, S.W. and Heidger, P.M. (1979): Fine structural studies of the rat vas deferens. Anat. Rec., 194: 159 - 180.

Krstic, R.V. (1984): Illustrated encyclopedia of human histology. 1 Aufl. Springer-Verlag Berlin. Heidelberg. New York. Tokyo.

Liebich, H.G. (1990): Funktionelle Histologie. Farbatlas und Kurzlehrbuch der Mikroskopischen Anatomie der Haussäugetiere, Schattauer. Stuttgart. New York.

Lohiya, N.K.; Srivastava, S.; Ansari, A.S. and Manivannan, A. (1999): Fine structure of the langur monkcy vas deferens and possible role of changes following vasectomy in the success or failure of the vasovasostomy. Adv. Contracept., 15: 337-350.

Murakami, M.; Sugita, A. and Hamasaki, M. (1982): Scanning electron microscopic observations of the vas deferens in man and monkey with special reference to spermiophagy in its ampullary region. Scann. Electron Microsc., pt 3: 1333 - 1339.

Niemi, M. (1965): The fine structure and histochemistry of the epithelial cells of the rat vas deferens. Acta Anat., 60: 207-219.

Osman, A.M. and Fahmy, M.F.A. (1970): Cited by Pal, C. and Bharadwaj, M.B.L. (1985).

Pal, C. and Bharadwaj, M.B.L. (1985): Anatomical studies on the vas deferens of buffaloes (Bubalus Bubalis) at different stages of maturity. Indian Vet. J., 62: 668 - 674.

Ramos, A.S. (1979): Morphologic variations along the length of the monkey vas deferens. Arch Andro1., 3: 187 - 196. 
Schiebler, T.H. und Peiper, U. (1984); Histologie: Lehrbuch der Cytologie, Histologie und mikroskopischen Anatomie des Menschen. Unter Brïcksichtigung der Histophysiologie, nach der amerikanischen Ausgabe von Junqueire, L.C und Carnciro, J. Springer-Verlag, Berlin. Heidelberg. New York. Tokyo.

Schummer, A.; Nickel, R. and Sack, W.O. (1979): The viscera of the domestic mammals. $2^{\text {nd }}$ revised Ed. Translated and revised from the $4^{\text {th }}$ German Ed. Verlag. Paul Parey.

Smollich, A. und Michel, G. (1985): Mikroskopische Anatomie der Haustiere. 1 Aufl. VEB Gustav Fischer Verlag Jena.

Srivastava, S.; Ansari, A.S. and Lohiya, N.K. (2000): Ultrastructure of langur monkey epididymis prior to and following vasectony and vasovasostomy. Eur. J. Morphol, 38: 24 - 33 .

Trautman, A. and Fiebiger, J. (1957): Fundamentals of the histology of domestic animals. Translated and Revisedn from $8^{\text {th }}$ and $9^{\text {th }}$ Germany Eđition. Comstock Publishing Associates, Ithaca. New York.

Trotter, D.M. (1959): Histological observations of the genitalia of the immature, the casterated, and the mature bovine male. Am. J. Vet. Res., 20: 213-222.

Verhoeff, F.H. (1908): Some new staining methods of wide applicability. Including a rapid differential stain for elastic tissue. J. Am. Med. Assoc., 50: 876-877. Cited by Bancroft, et al. (1996).

Weiss, L. (1983): Histology: Cell and tissue biology. $5^{\text {th }}$ Ed, Macmillan Press.

Wrobel, K.H. and Dellmann, H.D. (1993): Male reproductive system. In textbook of veterinary histology. Edited by Dellmann, H.D. $4^{\text {th }}$ Ed. Lea \& Fiebiger. Philadelphia.

\section{LEGENDS}

Fig. 1: Photograph showing the topography of the ductus deferens of the donkey. Left side (Reflected testis with spermatic cord after removal of the left pelvic limb). Extra-abdominal part (arrow), abdominal part (double arrows), ampulia ductus deferens (asterisk), vaginal ring (arrowhead). Tail of the epididymis (e), left \& right testes $\left(\mathrm{t}_{1}, \mathrm{t}_{2}\right)$, vascular part of spermatic cord (vs), penis (p), seminal vesicle (sv), prostate gland (pg), rectum ( $r$, ureter (u), urinary bladder (ub), abdominal wall (aw), pubis (pb), ischium (sc) and right thigh (th). 
Fig. 2: Photomicrograph of a cross-sectioned extra-abdominal part of the ductus deferens of the donkey, showing the general arrangement of its layers. Lumen (L), muscosal folds (arrowhead), lamina propria-submucosa (Lp), tunica muscularis ( $\mathrm{Tm})$, tunica serosa (Ts), subserosal layer with longitudinally oriented smooth muscle (arrow), muscular-band (thick arrow), cone-shaped expansion of the subserosa at the mesoductus (double asterisks) and its opposite side (asterisk) containing the various vessels (v), which gives off branches to the muscular coat (double arrows), measoductus (Md). Trichrome stain. X Oc. 10; Obj. 2.5 .

Figs. 3 \& 4: Photomicrographs showing variations in the luminal diamater (L), height of the mucosal folds (arrowhead) and thickness of the lamina propria-submucosa (Lp) between the extra-abdominal (3) and abdominal part (4) of the ductus deferens of the donkey. Tunica muscularis (Tm). Trichrome stain. X Oc. 10; Obj. 5. Inset: Higher magnification of the epithelial lining of the extra-abdominal part of the vas deferens of the donkey. Hx \& E. X Oc. 10; Obj. 40.

Fig. 5: Transmission electron micrograph of the apical portion of two principal cells of the abdominal part of the ductus deferens of the donkey, showing stereocilia (arrow), pinocytotic vesicles (arrowhead). Lumen (L). X 32727.

Figs. 6 \& 7: Photomicrographs of the mucosa of the extra-abdominal (6) and abdominal part (5) of the ductus deferens of the donkey, showing variations in height of the mucosal folds (f), pseudostratified columnar epithelium decreases in height towards the tip of the fold (asterisk) and stereocilia (arrowhead). Lumen (L), lamina propria-sumbucosa with dense collagenous fibers (green colouration), blood capillaries (arrow). Trichrome stain. X Oc. 10; Obj. 20.

Fig. 8: Photomicrograph of the extra-abdominal part of the ductus deferens, showing the characteristic girdle-like arrangement of the elastic fibers (arrow) within the outermost part of the lamina propria-submucosa. Lumen (L), mucosal folds (arrowhead), tunica muscularis (Tm). Verhoeff's stain. X Oc. 10; Obj. 5.

Fig. 9: Photomicrograph of the abdominal part of the ductus deferens, showing dense network of elastic fibers (black staining) in the outermost part of the lamina propria-submucosa. Elastic fibers extend into the tunica muscularis (arrow). Verhoeff's stain. $X$ Oc. 10; Obj. 20. 
Fig. 10: Photomicrograph of the extra-abdominal part of the ductus deferens, showing reticular fibers under the epithelial lining (arrow). Lamina propria-submucosa with dense collagenous fibers (brown colouration). Gomori's stain. X Oc. 10; Obj. 20.

Figs. 11 \& 12: Photomicrographs showing the characteristic interwoven arrangement of the inner (double asterisks) and outer longitudinal layers (asterisk) of the tunica muscularis of the extra-abdominal (11) and abdominal part (12). Lumen (L), muscosal folds (arrowhead), lamina propria-submucosa (arrow), collagenous fibers between the muscular bundles (green colouration), tunica serosa (Ts) with its longitudinally arranged muscle fibers (double arrows) and mesothelium (double arrowheads). 11: $\mathrm{Hx} \& \mathrm{E} ; 12$ : Trichrome stain. X Oc. 10; Obj. 5.

Fig. 13: Photomicrograph showing the network arrangement of the reticular fibers (black colouration) around the individual muscle fibers of the inner (A) and outer (B) muscular layers of the abdominal part of the ductus deferens. Collagenous fibers (brown colouration). Gomori's stain. X Oc. 10; Obj. 20.

Figs. 14 \& 15: Photomicrographs showing the cone-shaped expansions (asterisk) of the tunica serosa at the mesoductus (15) and opposite side (14) of the ductus deferens, containing various vessels within dense collagenous fibers. Collagenous band (arrow), thick muscular band (thick arrow), few muscle fibers towards the mesoductus (arrowhead), tunica muscularis (Tm), mesothelium (double arrows), mesoductus (Md). Trichrome Stain. 11: X Oc. 10; Obj. 5\& 12: X Oc. 10. Obj. 2.5

Figs. 16 \& 17: Photomicrographs of the extra-abdominal part of the ductus deferens (laterally), showing the tunica serosa with its mesothelium (arrowhead), and submesothelial layer (asterisk). Dense collagenous fibers [green (16) \& brown colouration (17)] containing longitudinally-oriented smooth muscle fibers (arrow). Network of reticular fibers (black colouration) surrounding the individual muscle fibers, nerve fibers (Nf), outer longitudinal layer of the tunica musculairs (Tm). 16: Trichrome stain; 17; Gomori's stain. X Oc. 10; Obj. 20.

Figs. 18-21: Photomicrographs of the tunica serosa and the mesoductus of the extra-abdominal part of the ductus deferens of the donkey. 
18: Tunica serosa at the opposite side of the mesoductus showing few fine elastic fibers (arrowhead). Mesothelium (arrow), muscular-band (thick arrow). Verhoeff's stain. X Oc. 10; Obj. 20.

19: Tunica serosa (latterally) showing increased amount of fino elastic fibers within its outermost part (arrowhead) and mesothelium (arrow). Verhoeff's stain. X Oc. 10; Obj. 20.

20: Mesoductus with numerous fine elastic fibers (arrowhead), mesothelium (arrow). Verhoeff's stain. X Oc. 10; Obj. 10.

21: Mesoductus showing no positively stained reticular fibers. Collagenous fibers (brown colouration). Gomori's stain. X Oc. 10 ; Obj. 10. 
Assiut Vet. Med. J. Vol. 49 No. 97 . April 2003

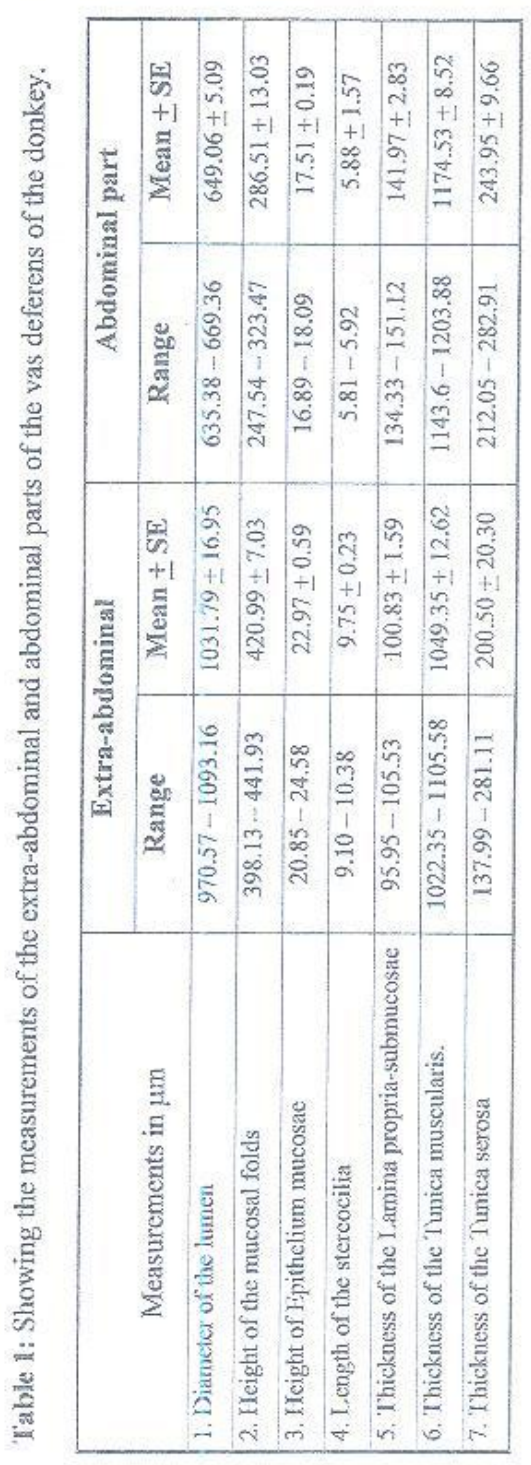


Assiut Vel. Med.J. Vol. 49 No. 97 . April 2003

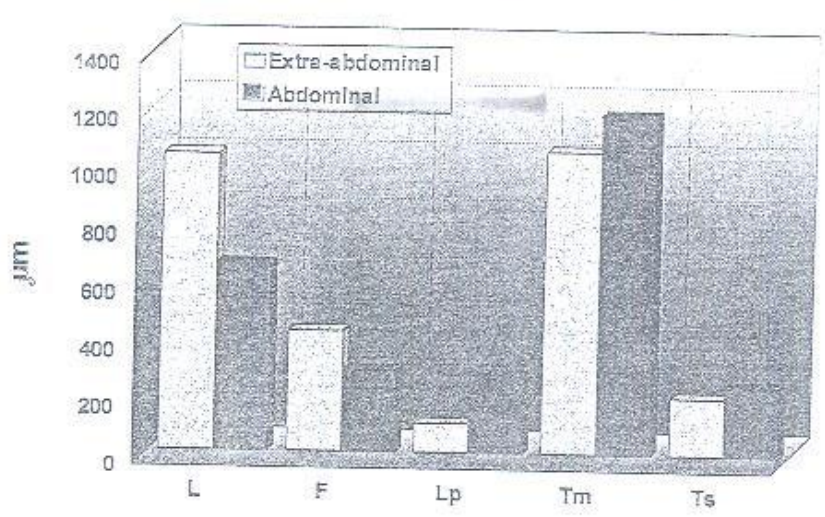

(a)

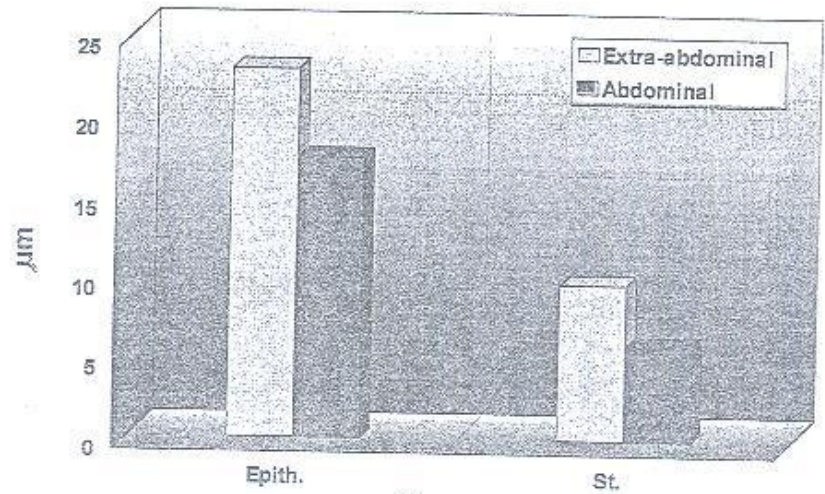

(b)

Histogram 1a \& b: Showing the correlation between the thickness of the different layers as well as the diameter of the lumen (L), height of the mucosal folds (F), height of lamina epithelialis muscosae (Epith.) and stereocilia (St) of the extra-abdominal and abdominal parts of the ductus deferens of the donkey.

Lamina propria-submucosae (Lp), Tunica muscularis (Tm), Tunica serosa (Ts) 
Assiut Vet. Med. J. Vol. 49 No. 97. April 2003

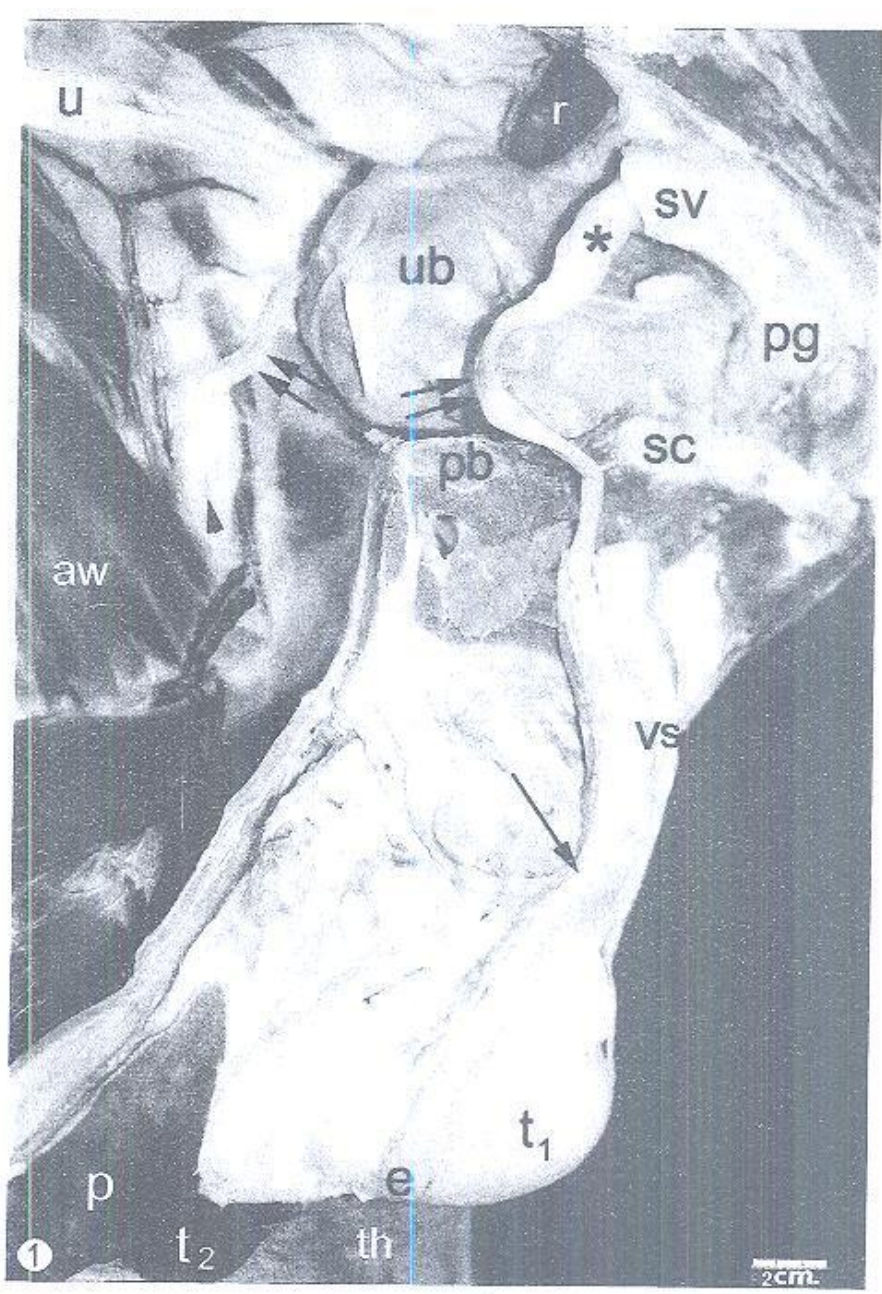


Assiut Vet. Med, J. Vol. 49 No. 97, April 2003

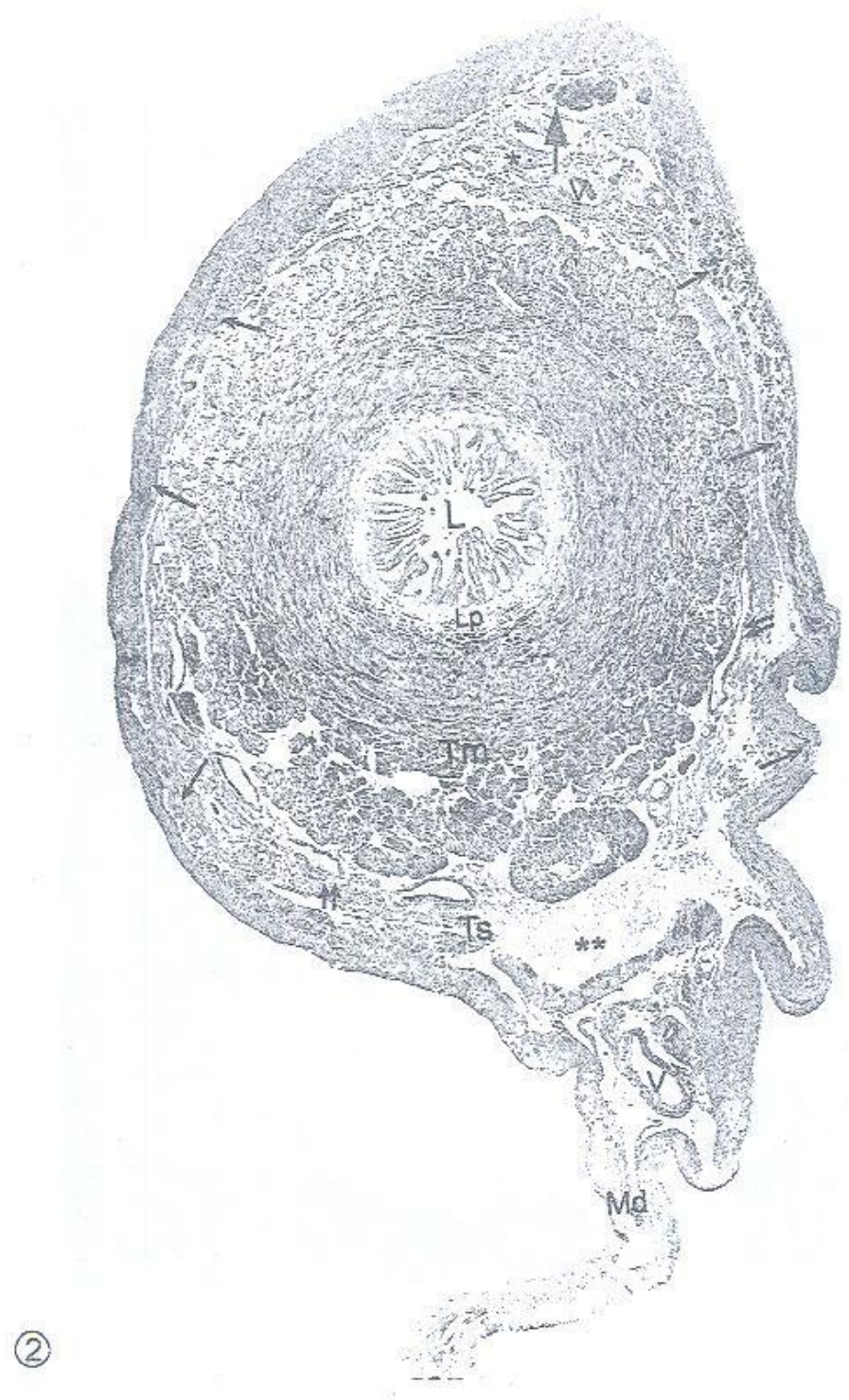


Assiul Vet. Med. J. Vol. 49 No. 97, April 2003

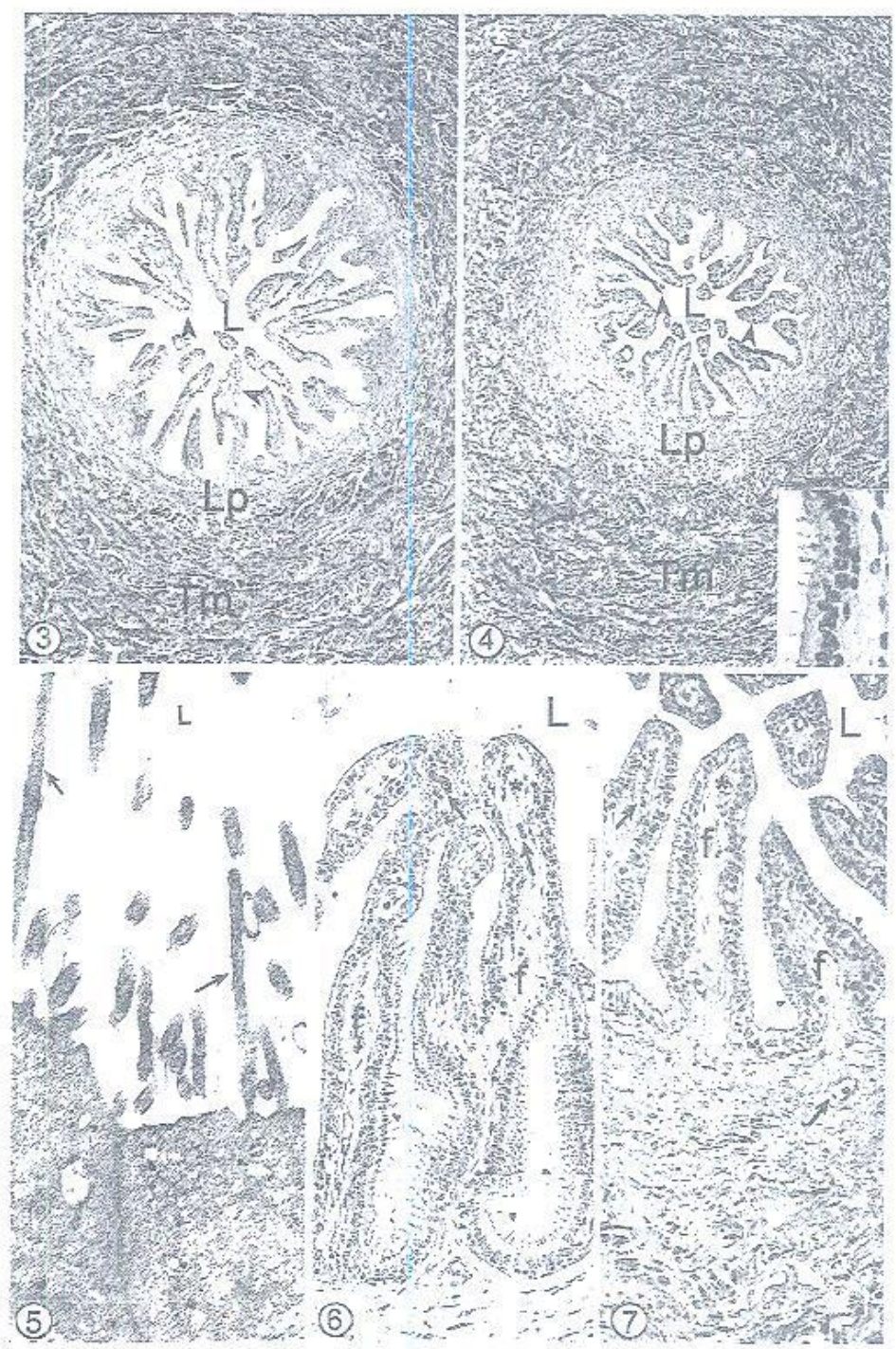


Assiut Vet. Med.J. Vol. 49 No. 97. April 2003
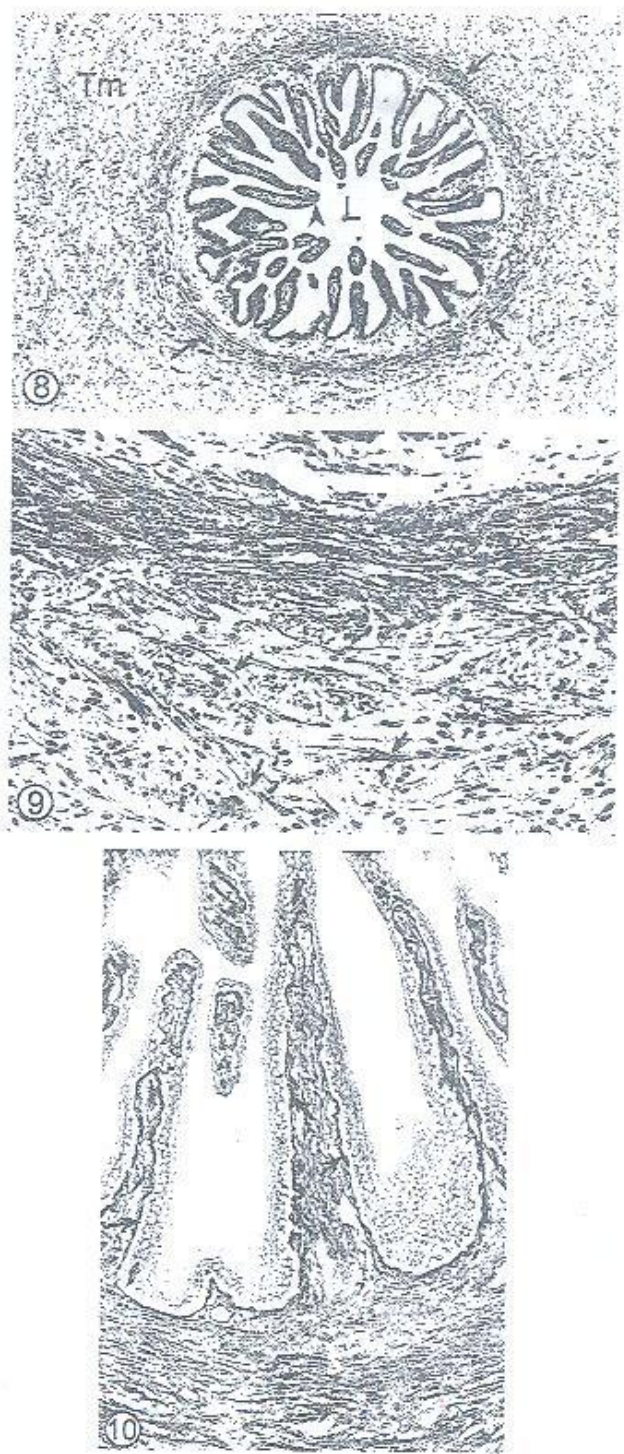
Assiut Vel. Med.J. Vol. 49 No. 97, April 2003
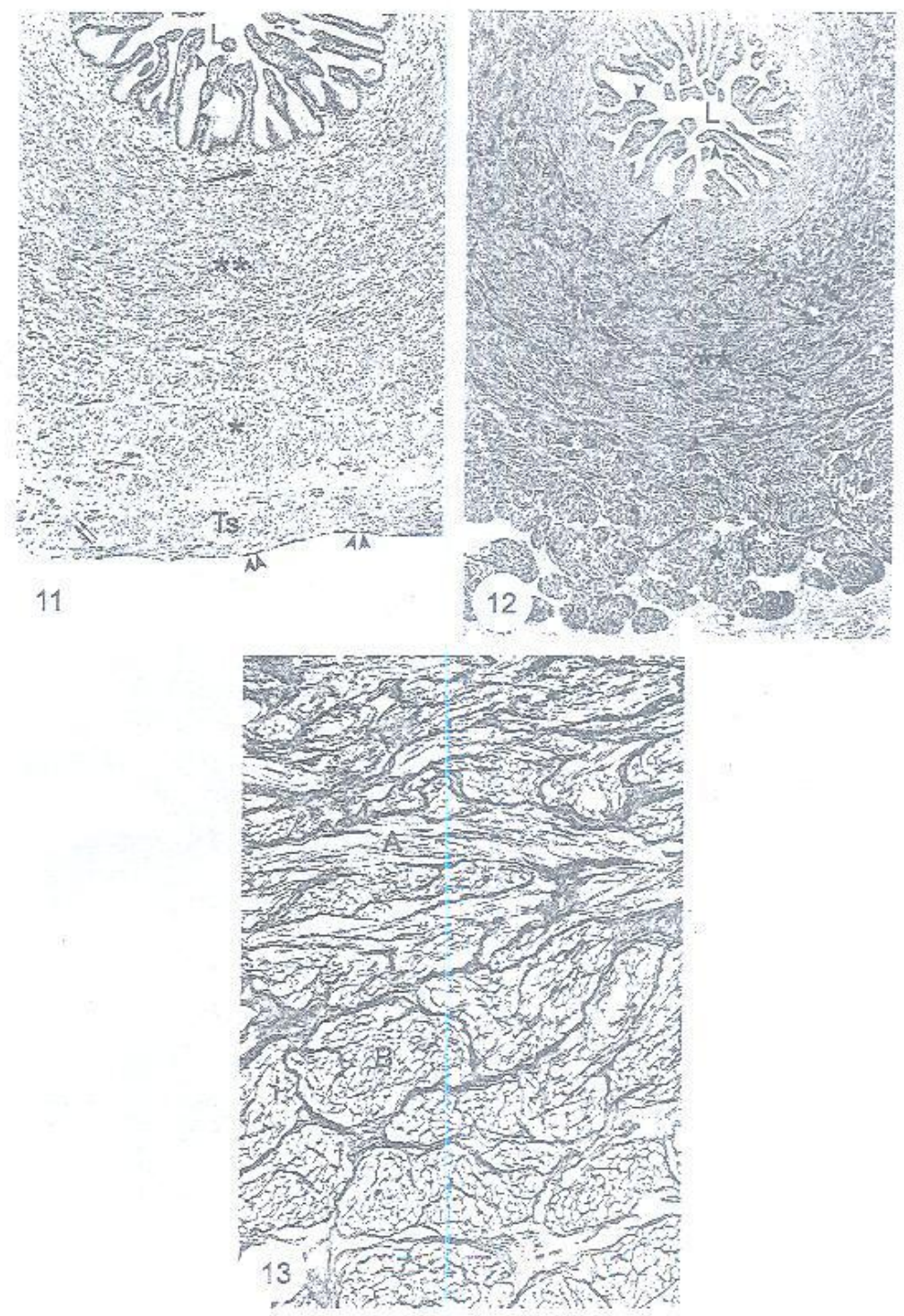
Assiut Vet.Med. J. Vol. 49 No. 97, April 2003
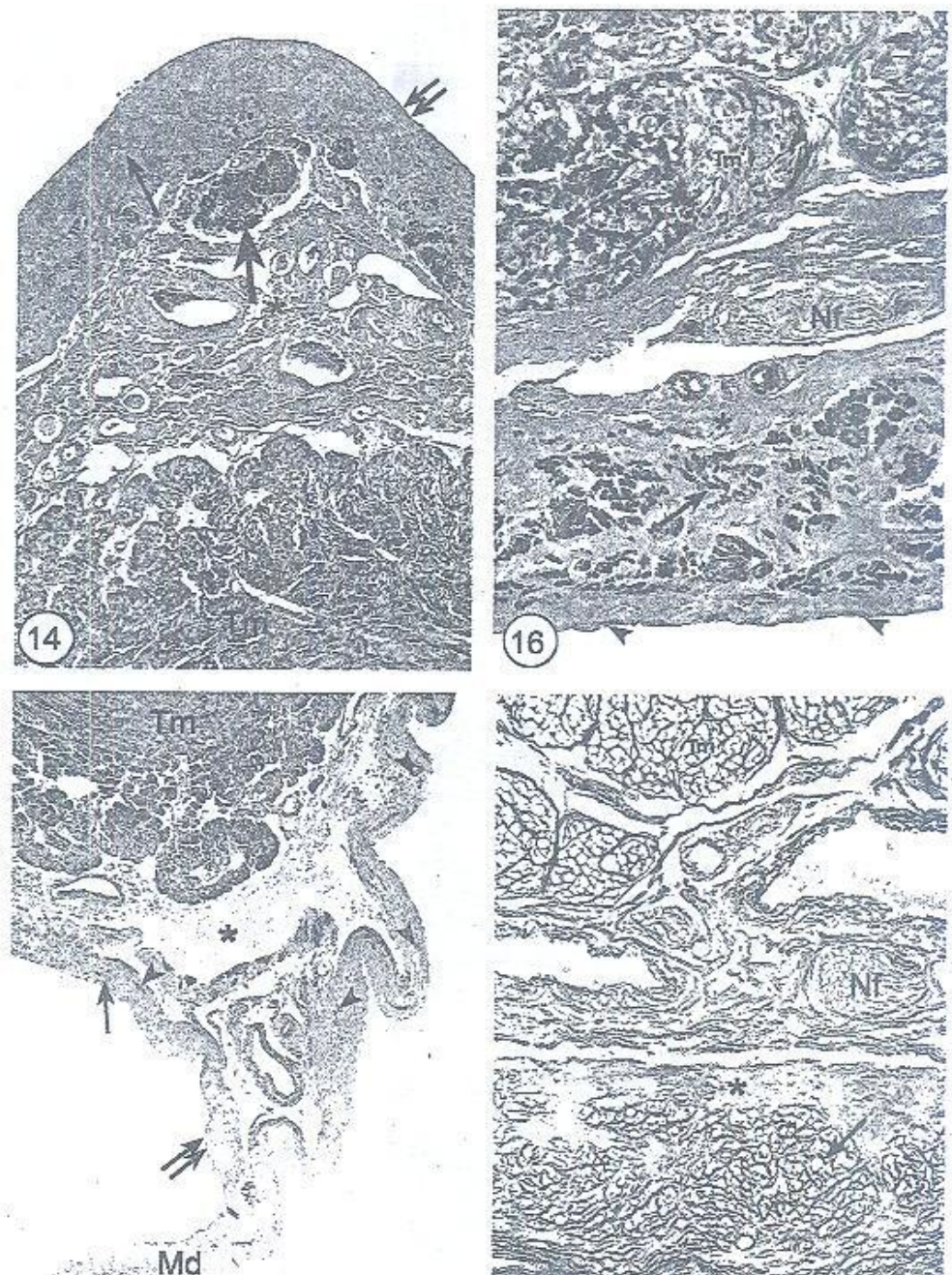

(15)

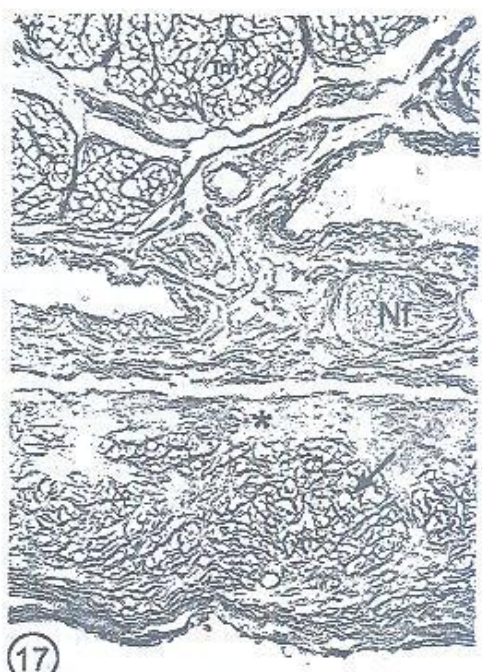



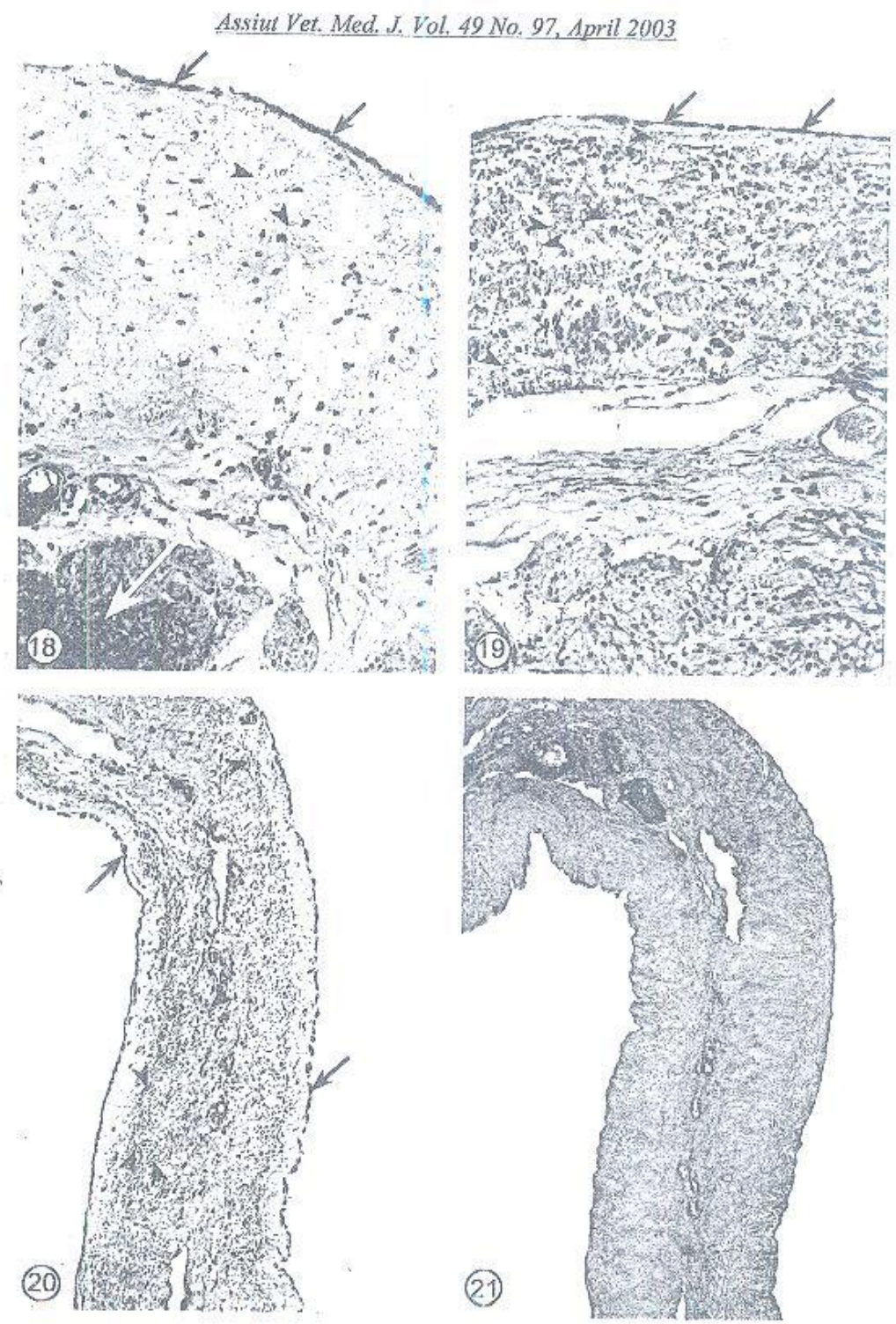